\title{
Quantitative assessment of the bidirectional relationships between diabetes and depression
}

\author{
Qi-Shuai Zhuang ${ }^{1}$, Liang Shen ${ }^{1}$, Hong-Fang $\mathrm{Ji}^{1}$ \\ ${ }^{1}$ Shandong Provincial Research Center for Bioinformatic Engineering and Technique, School of Life Sciences, Shandong \\ University of Technology, Zibo, P. R. China \\ Correspondence to: Liang Shen, email: shen@sdut.edu.cn \\ Hong-Fang Ji, email: jhf@sdut.edu.cn \\ Keywords: diabetes, depression, risk, bidirectional relationships \\ Received: November 04, $2016 \quad$ Accepted: January 09, 2017 \\ Published: February 03, 2017
}

\section{ABSTRACT}

Diabetes and depression impose an enormous public health burden and the present study aimed to assess quantitatively the bidirectional relationships between the two disorders. We searched databases for eligible articles published until October 2016. A total of 51 studies were finally included in the present bidirectional metaanalysis, among which, 32 studies were about the direction of depression leading to diabetes, and 24 studies about the direction of diabetes leading to depression. Pooled results of the 32 eligible studies covering 1274337 subjects showed that depression patients were at higher risk for diabetes (odds ratio $(O R)=1.34,95 \%$ confidence intervals $(\mathrm{CI})=[1.23,1.46])$ than non-depressive subjects. Further gender-subgroup analysis found that the strength of this relationship was stronger in men $(O R=1.63$, $95 \% \mathrm{CI}=[1.48,1.78])$ than in women $(\mathrm{OR}=1.29,95 \% \mathrm{CI}=[1.07,1.51])$. For the direction of diabetes leading to depression, pooled data of 24 articles containing 329658 subjects showed that patients with diabetes were at higher risk for diabetes $(\mathrm{OR}=1.28,95 \% \mathrm{CI}=[1.15,1.42])$ than non-diabetic subjects. The available data supports that the relationships between diabetes and depression are bidirectional and the overall strengths are similar in both directions. More mechanistic studies are encouraged to explore the molecular mechanisms underlying the relationships between the two diseases.

\section{INTRODUCTION}

Diabetes is a chronic metabolic disease with increasing prevalence worldwide nowadays owing to the lifestyle modifications and increasing life expectancy [1]. According to the International Diabetes Federation, 415 million adults have diabetes and this figure is expected to rise to 642 million by 2040 [2]. As high blood glucose levels can damage blood vessels, nerves, eyes and kidneys, patients with diabetes may suffer from a number of serious complications. Depression is a common psychiatric mood disorder with increasing prevalence and is one of the largest single causes of disability around the world [3].

Diabetes and depression carry a large public health burden presently and also a heavy burden on health budgets in the future. In recent years, accumulating studies indicate the close associations between the two chronic diseases, diabetes and depression [4-7]. It is found that comorbid diabetes and depression is common, which results in significant detrimental impact on health outcomes, including a significantly increased risk of mortality and increased healthcare cost [8]. Although there is a high rate of comorbid depression in patients with diabetes, it is unrecognized and untreated largely [9, 10]. Moreover, the prevalence of diabetes and depression differs in men and women. Women are about twice as likely as men to develop depression, while the prevalence of diabetes is higher in men than women [11, 12]. Thus, the present study aimed to perform a bidirectional random effects meta-analysis to quantitatively assess the strength of the relationships between diabetes and depression, and to examine the difference of the strength in males and females, to provide implications for future interventional studies of the two diseases. 
Table 1: Characteristics of the studies included in the analysis of risk of diabetes in patients with depression

\begin{tabular}{|c|c|c|c|c|c|c|}
\hline References & Country & Subjects & Age & Weight (\%) & OR & $95 \% \mathrm{CI}$ \\
\hline Deschênes 2016 [13] & Canada & 2486 & $40-69$ & 0.17 & 1.61 & $0.44-5.87$ \\
\hline Freitas 2016 [14] & England & 4454 & $50+$ & 1.10 & 1.29 & $0.63-2.64$ \\
\hline Khambaty 2016 [15] & US & 2156 & $60+$ & 5.05 & 1.18 & $0.95-1.46$ \\
\hline Koyanagi 2016 [16] & Spain & 201337 & $18+$ & 3.63 & 1.57 & $1.21-2.03$ \\
\hline Chen 2013 [17] & China & 11694 & $60.1 \pm 13.2$ & 5.25 & 2.02 & $1.80-2.27$ \\
\hline Bhowmik 2012 [18] & Bangladesh & 2293 & $20+$ & 0.65 & 3.52 & $2.42-5.12$ \\
\hline Chien 2012 [19] & China & 766427 & $18+$ & 6.04 & 1.53 & $1.39-1.69$ \\
\hline Nichols 2011 [20] & US & 58056 & $50+$ & 6.46 & 1.10 & $1.02-1.20$ \\
\hline Karakus 2011 [21] & US & 12652 & $51-61$ & 2.30 & 1.50 & $1.01-2.24$ \\
\hline Pan 2010 [22] & US & 65381 & $50-75$ & 6.23 & 1.17 & $1.05-1.30$ \\
\hline Demakakos 2010 [23] & UK & 6111 & $50+$ & 2.54 & 1.62 & $1.15-2.29$ \\
\hline Atlantis 2010 [24] & Australia & 1000 & $65+$ & 0.61 & 2.29 & $1.28-4.10$ \\
\hline Campayo 2010 [25] & Spain & 3521 & $55+$ & 1.52 & 1.65 & $1.02-2.66$ \\
\hline Golden 2008 [26] & US & 5201 & $45-84$ & 3.71 & 1.21 & $0.87-1.67$ \\
\hline Eriksson 2008 [27] & Sweden & 2127 & $35+$ & 0.37 & 1.60 & $0.60-4.30$ \\
\hline Eriksson 2008 [27] & Sweden & 3100 & $35+$ & 2.14 & 0.70 & $0.30-1.60$ \\
\hline Engum 2007 [28] & Norway & 37291 & $30-89$ & 4.91 & 1.51 & $1.27-1.81$ \\
\hline Engum 2007 [28] & Norway & 37291 & $30-89$ & 2.25 & 1.17 & $0.70-1.95$ \\
\hline Carnethon 2007 [29] & US & 4681 & $65+$ & 2.33 & 1.57 & $1.07-2.29$ \\
\hline Brown 2005 [30] & Canada & 92677 & $20-50$ & 6.16 & 1.23 & $1.10-1.37$ \\
\hline Maty 2005 [31] & US & 6147 & $17-94$ & 4.24 & 1.08 & $0.79-1.47$ \\
\hline Mallon 2005 [32] & Sweden & 550 & $45-65$ & 0.48 & 1.30 & $0.40-3.60$ \\
\hline Mallon 2005 [32] & Sweden & 620 & $45-65$ & 0.70 & 0.90 & $0.30-2.90$ \\
\hline Everson-Rose 2004 [33] & US & 2662 & $42-52$ & 1.81 & 1.46 & $0.90-2.36$ \\
\hline van den Akker 2004 [34] & Netherlands & 68004 & $20-50$ & 5.49 & 0.98 & $0.79-1.21$ \\
\hline Palinkas 2004 [35] & US & 971 & $50-89$ & 0.39 & 2.50 & $1.29-4.87$ \\
\hline Kumari 2004 [36] & UK & 5807 & $35-55$ & 3.31 & 1.17 & $0.80-1.70$ \\
\hline Kumari 2004 [36] & UK & 2579 & $35-55$ & 2.38 & 1.03 & $0.60-1.80$ \\
\hline Golden 2004 [37] & US & 11615 & $45-64$ & 4.61 & 1.31 & $1.04-1.64$ \\
\hline Arroyo 2004 [38] & US & 72178 & $45-72$ & 5.10 & 1.22 & $1.00-1.50$ \\
\hline Carnethon 2003 [39] & US & 6190 & $25-74$ & 1.85 & 1.86 & $1.27-2.71$ \\
\hline Saydah 2002 [40] & US & 8870 & $32-86$ & 3.84 & 1.11 & $0.79-1.56$ \\
\hline Stellato 2000 [41] & US & 1156 & $40-70$ & 0.15 & 3.09 & $1.34-7.12$ \\
\hline Kawakami 1999 [42] & Japan & 2380 & $18-53$ & 0.31 & 2.32 & $1.06-5.08$ \\
\hline Eaton 1996 [43] & US & 1715 & $18+$ & 0.24 & 2.23 & $0.90-5.55$ \\
\hline Palinkas 1991 [44] & US & 1585 & $50+$ & 1.69 & 1.34 & $0.78-2.31$ \\
\hline
\end{tabular}




\section{RESULTS}

\section{Risk of diabetes in patients with depression}

Selection process of studies included in the present study was shown in Figure 1. There were 32 eligible studies covering 1274337 subjects included in the assessment of risk of diabetes in patients with depression. Table 1 showed the first author, year of publication, country, number of subjects, the odds ratio (OR) and the corresponding 95\% confidence intervals (CI), extracted from each study. The metaanalytic results were shown in Figure 2, which indicated that depression patients were at higher risk of developing diabetes $(\mathrm{OR}=1.34,95 \% \mathrm{CI}=[1.23,1.46])$. Statistically moderate heterogeneity was found among these studies $\left(p=0.000, I^{2}=68.4 \%\right)$.
Risk of diabetes in male patients with depression

Effects of gender on the strength of the bidirectional relationships between diabetes and depression were examined through further gendersubgroup analysis. A total of 10 studies were included in the male subgroup analysis. Table 2 listed the main characteristics about the number of male subjects, OR and the corresponding 95\% CI of each study. According to the meta-analytic results shown in Figure 3 , depression patients were at $63 \%$ increased risk for developing diabetes $(\mathrm{OR}=1.63,95 \% \mathrm{CI}=[1.48$, 1.78]) than non-depressive male subjects, and heterogeneity was not found among these studies $(p=$ $\left.0.446, I^{2}=0.0 \%\right)$.

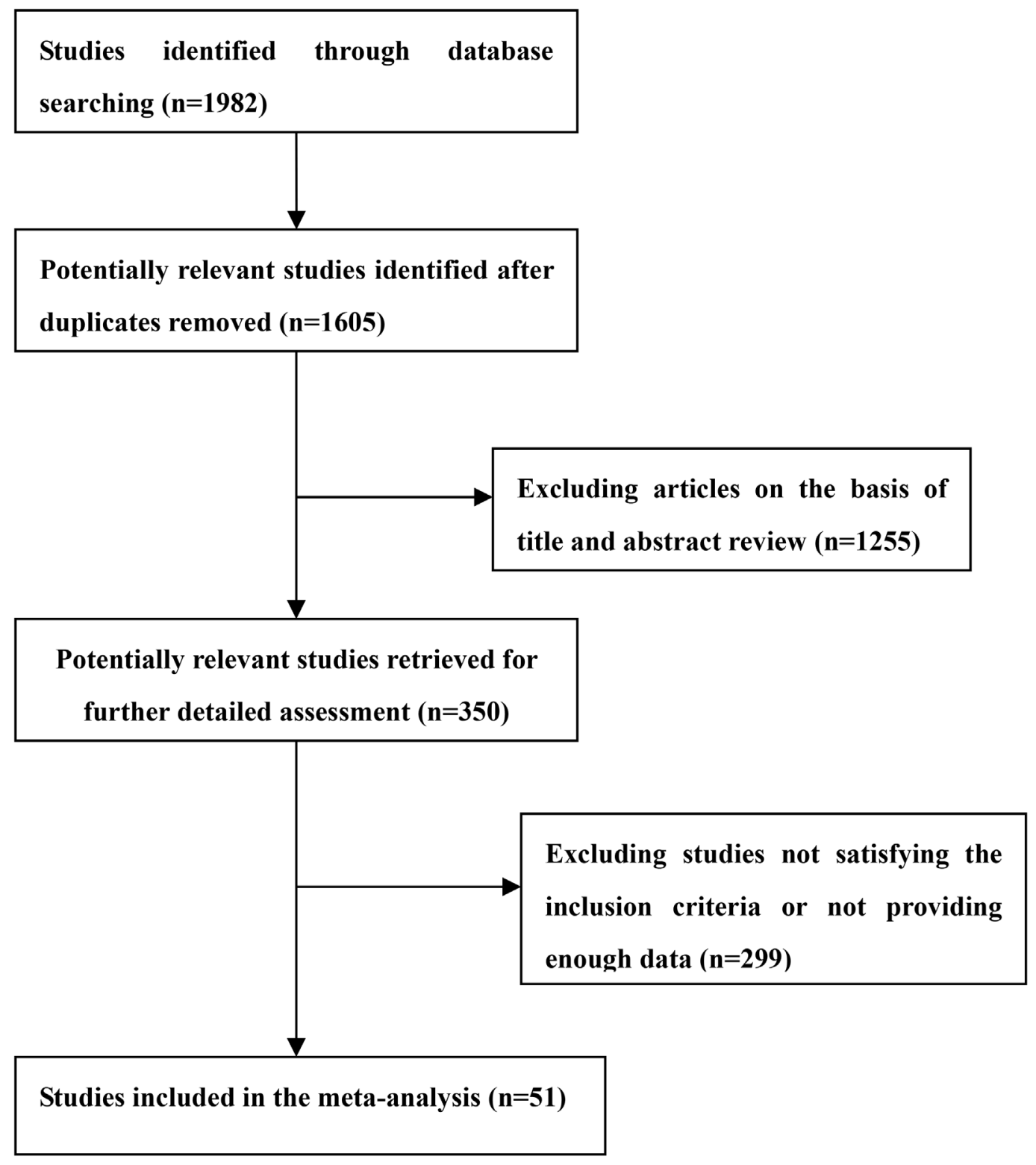

Figure 1: Selection of studies for inclusion in the meta-analysis. 
Table 2: Characteristics of the studies included in the male subgroup analysis of risk of diabetes in patients with depression

\begin{tabular}{lccccccc}
\hline References & Country & Subjects & Males \% & Age & Weight (\%) & OR & 95\% CI \\
\hline Chen 2013 [17] & China & 11694 & 40.3 & $60.1 \pm 13.2$ & 26.01 & 1.83 & $1.56-2.16$ \\
Chien 2012 [19] & China & 766427 & 48.8 & $18+$ & 34.63 & 1.72 & $1.48-2.00$ \\
Eriksson 2008 [27] & Sweden & 5227 & 40.7 & $35+$ & 0.68 & 1.60 & $0.60-4.30$ \\
Engum 2007 [28] & Norway & 37291 & 47.2 & $30-89$ & 17.57 & 1.42 & $1.11-1.84$ \\
Engum 2007 [28] & Norway & 37291 & 47.2 & $30-89$ & 2.49 & 1.26 & $0.62-2.56$ \\
Mallon 2005 [32] & Sweden & 1170 & 47 & $45-65$ & 0.91 & 1.30 & $0.40-3.60$ \\
van den Akker 2004 [34] & Netherlands & 68004 & 48.8 & $20-50$ & 4.71 & 1.78 & $1.21-2.62$ \\
Kumari 2004 [36] & US & 8386 & 69.2 & $35-55$ & 11.56 & 1.17 & $0.80-1.70$ \\
Stellato 2000 [41] & US & 1156 & 100 & $40-70$ & 0.28 & 3.09 & $1.34-7.12$ \\
Kawakami 1999 [42] & Japan & 2380 & 100 & $18-53$ & 0.58 & 2.32 & $1.06-5.08$ \\
Palinkas 1991 [44] & US & 1585 & 46.7 & $50+$ & 0.57 & 2.04 & $0.85-4.90$ \\
\hline
\end{tabular}

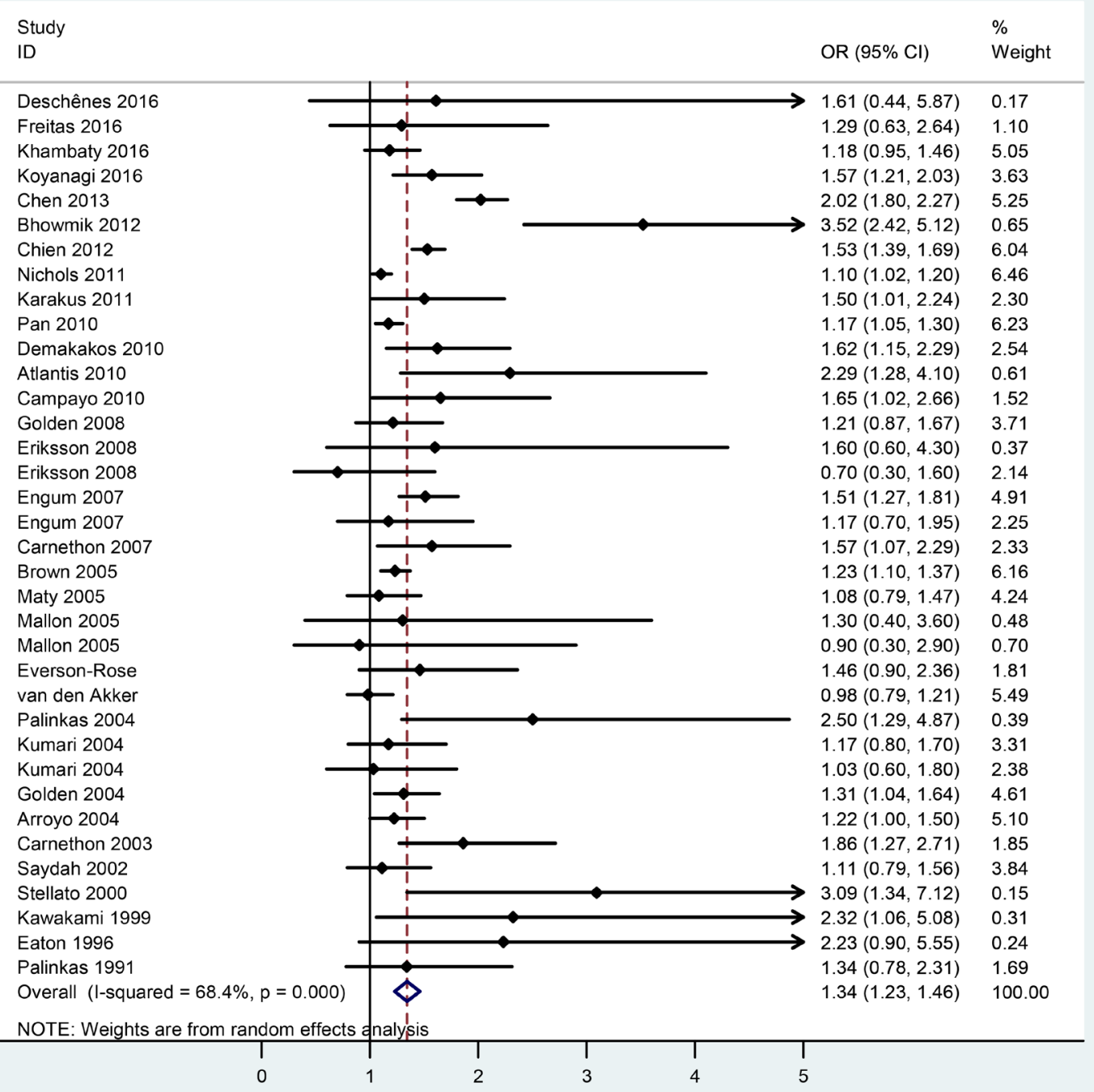

Figure 2: Forest plots of risk of diabetes in patients with depression. 
Table 3: Characteristics of the studies included in the female subgroup analysis of risk of diabetes in patients with depression

\begin{tabular}{lccccccc}
\hline References & Country & Subjects & Females \% & Age & $\begin{array}{c}\text { Weight } \\
\mathbf{( \% )}\end{array}$ & OR & 95\% CI \\
\hline Chen 2013 [17] & China & 11694 & 59.7 & $60.1 \pm 13.2$ & 10.41 & 2.23 & $1.89-2.62$ \\
Chien 2012 [19] & China & 766427 & 51.2 & $18+$ & 13.33 & 1.44 & $1.27-1.63$ \\
Pan 2010 [22] & US & 65381 & 100 & $50-75$ & 13.99 & 1.17 & $1.05-1.30$ \\
Eriksson 2008 [27] & Sweden & 5227 & 59.3 & $35+$ & 6.39 & 0.70 & $0.30-1.60$ \\
Engum 2007 [28] & Norway & 37291 & 52.8 & $30-89$ & 9.84 & 1.59 & $1.24-2.04$ \\
Engum 2007 [28] & Norway & 37291 & 52.8 & $30-89$ & 4.38 & 1.09 & $0.52-2.27$ \\
Mallon 2005 [32] & Sweden & 1170 & 53 & $45-65$ & 2.37 & 0.90 & $0.30-2.90$ \\
Everson-Rose 2004 [33] & US & 2662 & 100 & $42-52$ & 5.57 & 1.46 & $0.90-2.36$ \\
van den Akker 2004 [34] & Netherlands & 68004 & 51.2 & $20-50$ & 10.08 & 0.82 & $0.52-1.29$ \\
Kumari 2004 [36] & US & 8386 & 30.8 & $35-55$ & 6.97 & 1.03 & $0.60-1.80$ \\
Arroyo 2004 [38] & US & 72178 & 100 & $45-72$ & 12.30 & 1.22 & $1.00-1.50$ \\
Palinkas 1991 [44] & US & 1585 & 53.3 & $50+$ & 4.38 & 1.13 & $0.55-2.30$ \\
\hline
\end{tabular}

Study

$\begin{array}{ll} & \% \\ \text { OR }(95 \% \mathrm{Cl}) & \text { Weight }\end{array}$

ID

$1.83(1.56,2.16)$

26.01

Chen 2013

Chien 2012

Eriksson 2008

Engum 2007

Engum 2007

Mallon 2005

van den Akker 2004

Kumari 2004

Stellato 2000

Kawakami 1999

Palinkas 1991

Overall (I-squared $=0.0 \%, p=0.446$ )

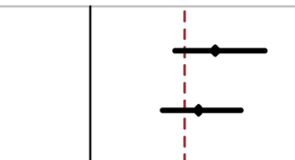

$1.83(1.56,2.16)$

34.63

$1.72(1.48,2.00)$

0.68

$1.60(0.60,4.30)$

17.57

$1.42(1.11,1.84)$

2.49

$1.26(0.62,2.56)$

$1.30(0.40,3.60) \quad 0.91$

$1.78(1.21,2.62) \quad 4.71$

$1.17(0.80,1.70) \quad 11.56$

$3.09(1.34,7.12) \quad 0.28$

$2.32(1.06,5.08) \quad 0.58$

$2.04(0.85,4.90) \quad 0.57$

$1.63(1.48,1.78) \quad 100.00$

NOTE: Weights are from random effects analysis

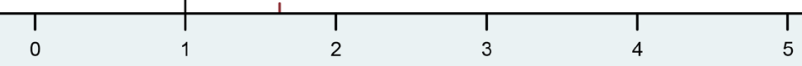

Figure 3: Forest plots of risk of diabetes in male patients with depression. 


\section{Risk of diabetes in female patients with depression}

There were 11 eligible studies included in the female subgroup analysis. Table 3 showed the extracted information of each eligible study. The pooled OR indicated that depression patients were at higher risk for diabetes $(\mathrm{OR}=1.29,95 \% \mathrm{CI}=[1.07,1.51]$, Figure 4$)$ than non-depressive female subjects and statistically moderate heterogeneity was found among these studies ( $p=0.000$, $\left.I^{2}=75.3 \%\right)$.

\section{Risk of depression in patients with diabetes}

For the direction of diabetes leading to depression, there were a total of 24 eligible studies covering 329658 subjects. Table 4 collected the extracted main characteristics, including the first author, year of publication, country, and number of subjects, OR and the corresponding $95 \% \mathrm{CI}$ of each included study. The pooled results were shown in Figure 5, which indicated that patients with diabetes were at higher risk for developing depression $(\mathrm{OR}=1.28,95 \% \mathrm{CI}=[1.15,1.42])$ than nondiabetic subjects with statistically significant heterogeneity among these studies ( $p=0.000, I^{2}=62.5 \%$ ).

\section{Publication bias}

Funnel plot and Egger's test were employed to estimate the publication bias among the included studies. The funnel plot showed generally symmetrical distribution, suggesting no evidence of publication bias for the outcomes in both directions. Egger's test also
Study

ID

Chen 2013
Chien 2012
Pan 2010
Eriksson 2008
Engum 2007
Engum 2007
Mallon 2005
Everson-Rose 2004

van den Akker 2004

Kumari 2004

Arroyo 2004

Palinkas 1991

Overall $($ I-squared $=75.3 \%, p=0.000)$

NOTE: Weights are from random effects analysis
$\%$

OR $(95 \% \mathrm{Cl}) \quad$ Weight

\begin{tabular}{ll}
$2.23(1.89,2.62)$ & 10.41 \\
$1.44(1.27,1.63)$ & 13.33 \\
$1.17(1.05,1.30)$ & 13.99 \\
$0.70(0.30,1.60)$ & 6.39 \\
$1.59(1.24,2.04)$ & 9.84 \\
$1.09(0.52,2.27)$ & 4.38 \\
$0.90(0.30,2.90)$ & 2.37 \\
$1.46(0.90,2.36)$ & 5.57 \\
$0.82(0.52,1.29)$ & 10.08 \\
$1.03(0.60,1.80)$ & 6.97 \\
$1.22(1.00,1.50)$ & 12.30 \\
$1.13(0.55,2.30)$ & 4.38 \\
$1.29(1.07,1.51)$ & 100.00 \\
& \\
\hline
\end{tabular}

Figure 4: Forest plots of risk of diabetes in female patients with depression. 
Table 4: Characteristics of the studies included in the analysis of risk of depression in patients with diabetes

\begin{tabular}{|c|c|c|c|c|c|c|}
\hline References & Country & Subjects & Age & Weight (\%) & OR & $95 \% \mathrm{CI}$ \\
\hline van Dooren 2016 [45] & Netherlands & 862 & $40-75$ & 0.26 & 3.15 & $1.49-6.67$ \\
\hline Westra 2016 [46] & Netherlands & 527 & $60-87$ & 0.66 & 1.96 & $0.94-4.10$ \\
\hline Meurs 2015 [47] & Netherlands & 90686 & $18-93$ & 6.41 & 1.39 & $1.10-1.76$ \\
\hline Deschênes 2015 [48] & Canada & 17623 & $15+$ & 6.89 & 1.18 & $0.92-1.52$ \\
\hline Bruce 2015 [49] & Australia & 184 & $70.2 \pm 10.1$ & 0.16 & 2.77 & $1.00-7.70$ \\
\hline Islam 2015 [50] & Australia & 1182 & $50.4 \pm 11.4$ & 0.09 & 6.40 & $3.40-12.30$ \\
\hline Chen 2013 [17] & China & 33914 & $60.1 \pm 13.2$ & 6.81 & 1.43 & $1.16-1.77$ \\
\hline Hamer 2011 [51] & UK & 4338 & $62.9 \pm 9$ & 3.04 & 1.52 & $1.01-2.30$ \\
\hline Pan 2010 [22] & US & 7415 & $50-75$ & 9.88 & 1.29 & $1.18-1.40$ \\
\hline O’Connor 2009 [52] & US & 17076 & $40+$ & 6.81 & 1.46 & $1.19-1.80$ \\
\hline Almawi 2008 [53] & Bahrain & 275 & $31-60$ & 0.09 & 3.82 & $1.43-10.25$ \\
\hline Golden 2008 [26] & US & 5201 & $45-84$ & 4.09 & 1.52 & $1.09-2.12$ \\
\hline Luijendijk 2008 [54] & Netherlands & 2931 & $61+$ & 0.87 & 2.07 & $1.11-3.85$ \\
\hline Maraldi 2007 [55] & Italy & 2522 & $70-79$ & 7.38 & 1.31 & $1.07-1.61$ \\
\hline Engum 2007 [28] & Norway & 37291 & $30-89$ & 3.36 & 1.24 & $0.78-1.98$ \\
\hline Engum 2007 [28] & Norway & 37291 & $30-89$ & 0.97 & 1.56 & $0.73-3.31$ \\
\hline Kim 2006 [56] & $\begin{array}{l}\text { South } \\
\text { Korean }\end{array}$ & 521 & $65+$ & 1.39 & 1.00 & $0.40-2.50$ \\
\hline de Jonge 2006 [57] & Spain & 4803 & $55+$ & 5.75 & 1.41 & $1.08-1.83$ \\
\hline Brown 2006 [58] & Canada & 88776 & $20-95$ & 9.94 & 1.04 & $0.94-1.15$ \\
\hline Polsky 2005 [59] & US & 8387 & $51-61$ & 8.30 & 1.17 & $0.98-1.41$ \\
\hline Palinkas 2004 [35] & US & 971 & $50-89$ & 4.85 & 0.73 & $0.41-1.30$ \\
\hline Bisschop 2004 [60] & Netherlands & 1839 & $55-85$ & 7.96 & 0.73 & $0.53-1.00$ \\
\hline Rajala 1997 [61] & Finland & 734 & 55 & 0.83 & 2.10 & $1.20-4.00$ \\
\hline Wing 1990 [62] & US & 64 & $30-70$ & 2.84 & 1.96 & $0.70-2.05$ \\
\hline Weyerer 1989 [63] & Hungary & 1536 & $15+$ & 0.39 & 3.15 & $1.69-5.87$ \\
\hline
\end{tabular}

found low possibility of publication bias $(p=0.262$ for the direction of depression leading to diabetes and $p=0.326$ for the direction of diabetes leading to depression).

\section{DISCUSSION}

Diabetes and depression are two highly prevalent chronic diseases around the world, and increasing evidence indicates the high rates of co-occurrence of the two diseases. The present study was designed to conduct a quantitative assessment on the bidirectional relationships between the two diseases to provide directions for their prevention and treatment. It was found that there was a
$34 \%$ increased risk of developing diabetes in depression patients than non-depressive subjects, and a $28 \%$ increased risk of developing depression in patients with diabetes compared with non-diabetic subjects. Thus, the study provides evidence that the relationships between diabetes and depression are bidirectional with similar strengths in both directions.

The mechanisms accounting for the relationships between diabetes and depression should be multiple in terms of biological, psychological and socioeconomic determinants [64-66]. First, depression can be regarded as an additional risk factor for diabetes. Depression patients are less likely to be compliant with dietary and weight 
loss recommendations and are more prone to be lack of physical exercise, which can lead to worsening of obesity and insulin resistance, and thus may increase the risk of developing diabetes. Some drugs used to treat depression may lead to weight gain and obesity, which could make individuals susceptible to the development of diabetes $[67,68]$. Second, diabetes can also increase the risk of depression. For patients with diabetes, poor control of blood sugar, strict diet and physical exercise requirements, and treatment may increase the incidence of depression. It was found that chronic stress could cause hyper-activation of the hypothalamic-pituitary-adrenal axis and an increase in cortical, which has been proposed to be an important pathway to interpret the clinical relationships between diabetes and depression [69-71]. In addition, on the basis of the large-scale genome wide association studies about type 2 diabetes and major depressive disorder, we performed a bioinformatics analysis on the genetic overlap between the two diseases [72]. The overlapped single nucleotide polymorphisms and functional enrichment pathway of the annotated genes were identified, which provided clues for future treatment strategies for the two diseases [72].

Our analysis has several limitations. First, we analyzed the effect of gender on the risk of diabetes in patients with depression, while the current available data cannot permit us to perform the gender subgroup analysis for the direction of diabetes leading to depression. Second, as many studies did not specify the type of diabetes, we analyzed the overall relationships of diabetes with

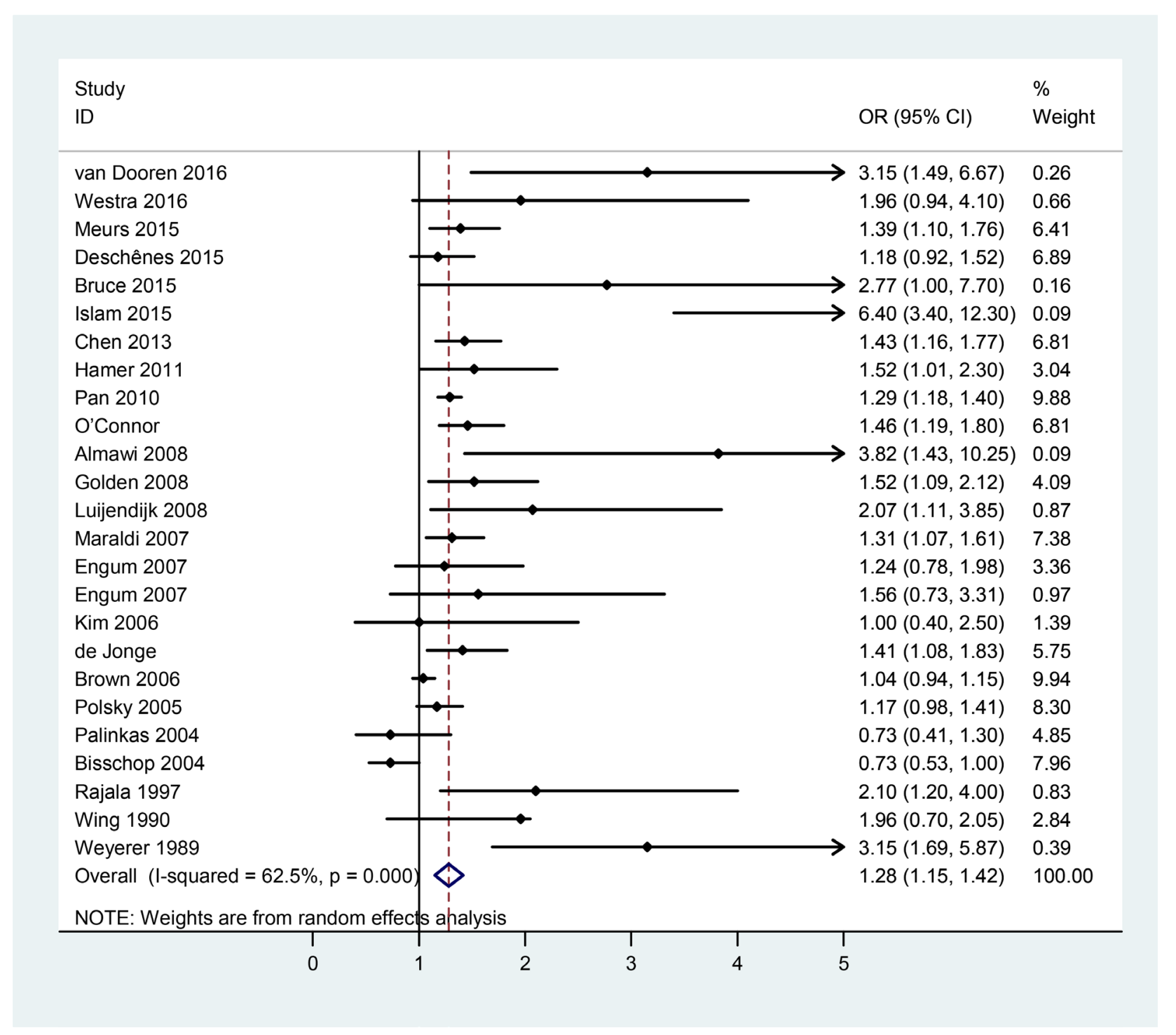

Figure 5: Forest plots of risk of depression in patients with diabetes. 
depression. Third, several case-control and cross-sectional studies were employed in the bidirectional analysis and thus we cannot exclude the recall and selection bias.

\section{MATERIALS AND METHODS}

\section{Search strategy and selection criteria}

With the combination of the following terms "depression" or "depressive" and "diabetes", the Medline and PsycINFO databases were scanned for articles written in English and published in peer-reviewed journals up to October 2016. The conference proceedings and reference lists from retrieved articles were also screened to obtain additional relevant reports. Cohort, cross-sectional and case-control studies providing OR and $95 \% \mathrm{CI}$, or enough data to calculate the two parameters, of risk of developing diabetes in patients with depression or vice versa, were eligible for inclusion. Two investigators (QSZ and LS) independently screened the literature and extracted information from the eligible studies. Any disagreement was resolved by consensus. The flow chart in Figure 1 summarized the references selection process. In total, 51 studies were finally included in the bidirectional analysis [13-63], among which, 32 studies were about the risk of diabetes in patients with depression, and 24 studies were about the risk of depression in patients with diabetes.

\section{Meta-analytic methods}

The meta-analysis was performed for the extracted fully adjusted ORs employing the Stata statistical software version 12.0 (Stata Corp LP, College Station, Texas) with the random effects model. To assess the effect of gender on the relationships between diabetes and depression, the gender-subgroup analysis was further performed. Heterogeneity was evaluated employing Q-test and $I^{2}$ score. Funnel plot and Egger's test were used to examine the publication bias among the included studies.

\section{CONCLUSIONS}

In summary, the present quantitative assessmentprovides evidence that the relationships between diabetes and depression are bidirectional with similar strengths in both directions, which implies that physicians should be aware of the co-occurrence of depression and diabetes.

\section{ACKNOWLEDGMENTS}

This work was supported by the Shandong Provincial Science Foundation for Distinguished Young Scholars (Grant No. JQ201508), Key program of Shandong Provincial Science Foundation (Grant
No. ZR2015JL010) and Shandong Provincial Science Foundation (ZR2014CL008).

\section{CONFLICTS OF INTEREST}

The authors declared no potential conflicts of interest.

\section{REFERENCES}

1. Nathan DM. Clinical practice. Initial management of glycemia in type 2 diabetes mellitus. N Engl J Med. 2002; 347:1342-1349.

2. 7th Edition of the Diabetes Atlas, http://www.diabetesatlas. org.

3. World Health Organization. Mental health action plan: 2013-2020. Available at: http://apps.who.int/iris/bitstr eam/10665/89966/1/9789241506021_eng.pdf?ua=1.

4. Lustman PJ, Griffith LS, Clouse RE. Depression in adults with diabetes. Semin Clin Neuropsychiatry. 1997; 2:15-23.

5. Leone T, Coast E, Narayanan S, de Graft Aikins A. Diabetes and depression comorbidity and socio-economic status in low and middle income countries (LMICs): a mapping of the evidence. Global Health. 2012; 8:39.

6. Fisher EB, Chan JC, Nan H, Sartorius N, Oldenburg B. Co-occurrence of diabetes and depression: conceptual considerations for an emerging global health challenge. J Affect Disord. 2012; 142:S56-66.

7. Musselman DL, Betan E, Larsen H, Phillips LS. Relationship of depression to diabetes types 1 and 2: epidemiology, biology, and treatment. Biol Psychiatry. 2003; 54:317-329.

8. Moussavi S, Chatterji S, Verdes E, Tandon A, Patel V, Ustun B. Ustun Depression, chronic diseases, and decrements in health: results from the World Health Surveys. Lancet. 2007; 370:851-858.

9. Katon WJ. The comorbidity of diabetes mellitus and depression. Am J Med. 2008; 121:S8-15.

10. Hermanns N, Caputo S, Dzida G, Khunti K, Meneghini LF, Snoek F. Screening, evaluation and management of depression in people with diabetes in primary care. Prim Care Diabetes. 2013; 7:1-10.

11. Altemus M. Sex differences in depression and anxiety disorders: potential biological determinants. Horm Behav. 2006; 50:534-538.

12. Wild S, Roglic G, Green A, Sicree R, King H. Global prevalence of diabetes: estimates for the year 2000 and projections for 2030. Diabetes Care. 2004; 27:1047-1053.

13. Deschênes SS, Burns RJ, Graham E, Schmitz N. Prediabetes, depressive and anxiety symptoms, and risk of type 2 diabetes: A community-based cohort study. J Psychosom Res. 2016: 89:85-90.

14. Freitas C, Deschênes S, Au B, Smith K, Schmitz N. Risk of Diabetes in Older Adults with Co-Occurring Depressive 
Symptoms and Cardiometabolic Abnormalities: Prospective Analysis from the English Longitudinal Study of Ageing. PLoS One. 2016: 11.

15. Khambaty T, Callahan CM, Perkins AJ, Stewart JC. Depression and Anxiety Screens as Simultaneous Predictors of 10-Year Incidence of Diabetes Mellitus in Older Adults in Primary Care. J Am Geriatr Soc. 2016.

16. Koyanagi A, Oh H, Stubbs B, Haro JM, DeVylder JE. Epidemiology of depression with psychotic experiences and its association with chronic physical conditions in 47 lowand middle-income countries. Psychol Med. 2016: 27:1-12.

17. Chen P, Chan YT, Chen HF, Ko MC, Li CY. PopulationBased Cohort Analyses of the Bidirectional Relationship between Type 2 Diabetes and Depression. Diabetes Care. 2013; 36:376-382.

18. Bhowmik B, Binte Munir S, Ara Hossain I, Siddiquee T, Diep LM, Mahmood S, Mahtab H, Khan AK, Hussain A. Prevalence of Type 2 Diabetes and Impaired Glucose Regulation with Associated Cardiometabolic Risk Factors and Depression in an Urbanizing Rural Community in Bangladesh: A Population-Based Cross-Sectional Study. Diabetes Metab J. 2012; 36:422-432.

19. Chien IC, Wu EL, Lin CH, Chou YJ, Chou P. Prevalence of diabetes in patients with major depressive disorder: a population-based study. Compr Psychiatry. 2012; 53:569-575.

20. Nichols GA, Moler EJ. Cardiovascular disease, heart failure, chronic kidney disease and depression independently increase the risk of incident diabetes. Diabetologia. 2011; 54:523-526.

21. Karakus MC, Patton LC. Depression and the Onset of Chronic Illness in Older Adults: A 12-Year Prospective Study. J Behav Health Serv Res. 2011; 38:373-382.

22. Pan A, Lucas M, Sun Q, van Dam RM, Franco OH, Manson JE, Willett WC, Ascherio A, Hu FB. Bidirectional Association between Depression and Type 2 Diabetes in Women. Arch Intern Med. 2010; 170:1884-1891.

23. Demakakos P, Pierce MB, Hardy R. Depressive Symptoms and Risk of Type 2 Diabetes in a National Sample of Middle-Aged and Older Adults. Diabetes Care. 2010; 33:792-797.

24. Atlantis E, Browning C, Sims J, Kendig H. Diabetes incidence associated with depression and antidepressants in the Melbourne Longitudinal Studies on Healthy Ageing (MELSHA). Int J Geriatr Psychiatry. 2010; 25:688-696.

25. Campayo A, de Jonge P, Roy JF, Saz P, de la Cámara C, Quintanilla MA, Marcos G, Santabárbara J, Lobo A. Depressive Disorder and Incident Diabetes Mellitus: The Effect of Characteristics of Depression. Am J Psychiatry. 2010; 167:580-588.

26. Golden SH, Lazo M, Carnethon M, Bertoni AG, Schreiner PJ, Diez Roux AV, Lee HB, Lyketsos C. Examining a bidirectional association between depressive symptoms and diabetes. JAMA. 2008; 299:2751-2759.
27. Eriksson AK, Ekbom A, Granath F, Hilding A, Efendic S, Ostenson CG. Psychological Care Psychological distress and risk of pre-diabetes and Type 2 diabetes in a prospective study of Swedish middle-aged men and women. Diabet Med. 2008; 25:834-842.

28. Engum A. The role of depression and anxiety in onset of diabetes in a large population-based study. J Psychosom Res. 2007; 62:31-38.

29. Carnethon MR, Biggs ML, Barzilay JI, Smith NL, Vaccarino V, Bertoni AG, Arnold A, Siscovick D. Longitudinal association between depressive symptoms and incident type 2 diabetes mellitus in older adults. Arch Intern Med. 2007; 167:802-807.

30. Brown LC, Majumdar SR, Newman SC, Johnson JA. History of Depression Increases Risk of Type 2 Diabetes in Younger Adults. Diabetes Care. 2005; 28:1063-1067.

31. Maty SC, Everson-Rose SA, Haan MN, Raghunathan TE, Kaplan GA. Education, income, occupation, and the 34-year incidence (1965-99) of Type 2 diabetes in the Alameda County Study. Int J Epidemiol. 2005; 34:1274-1281.

32. Mallon L, Broman JE, Hetta J. High incidence of diabetes in men with sleep complaints or short sleep duration. Diabetes Care. 2005; 28:2762-2767.

33. Everson-Rose SA, Meyer PM, Powell LH, Pandey D, Torréns JI, Kravitz HM, Bromberger JT, Matthews KA. Depressive symptoms, insulin resistance and risk of diabetes in women at midlife. Diabetes Care. 2004; 27:2856-2862.

34. van den Akker M, Schuurman A, Metse-makers J, Buntinx F. Is depression related to subsequent diabetes mellitus? Acta Psychiatr Scand. 2004; 110:178-183.

35. Palinkas L, Lee P, Barrett-Commor E. A prospective study of type 2 diabetes and depressive symptoms in the elderly: the Rancho Bernardo Study. Diabetic Med. 2004; 21:1185-1191.

36. Kumari M, Head J, Marmot M. Prospective study of social and other risk factors for incidence of type 2 diabetes in the Whitehall II study. Arch Intern Med. 2004; 164:1873-1880.

37. Golden SH, Williams JE, Ford DE, Yeh HC, Paton Sanford C, Nieto FJ, Brancati FL. Depressive symptoms and the risk of type 2 diabetes: the Atherosclerosis Risk in Communities Study. Diabetes Care. 2004; 27:429-435.

38. Arroyo C, Hu F, Ryan L, Kawachi I, Colditz GA, Speizer FE, Manson J. Depressive symptoms and risk of type 2 diabetes in women. Diabetes Care. 2004; 27:129-133.

39. Carnethon MR, Kinder LS, Fair JM, Stafford RS, Fortmann SP. Symptoms of depression as a risk factor for incident diabetes: findings from the National Health and Nutrition Examination Epidemiologic Follow-Up Study, 1971-1992. Am J Epidemiol. 2003; 158:416-423.

40. Saydah SH, Brancati FL, Golden SH, Fradkin J, Harris MI. Depressive symptoms and the risk of type 2 diabetes mellitus in a US sample. Diabetes Metab Res Rev. 2003; 19:202-208. 
41. Stellato RK, Feldman HA, Hamdy O, Horton ES, McKinlay JB. Testosterone, sex hormone-binding globulin and the development of type 2 diabetes in middle-aged men: prospective results from the Massachusetts male aging study. Diabetes Care. 2000; 23:490-494.

42. Kawakami N, Takatsuka N, Shimizu H, Ishibashi H. Depressive symptoms and occurrence of type 2 diabetes among Japanese men. Diabetes Care. 1999; 22:1071-1076.

43. Eaton WW, Armenian H, Gallo J, Pratt L, Ford DE. Depression and risk for onset of type II diabetes: a prospective population-based study. Diabetes Care. 1996; 19:1097-1102.

44. Palinkas LA, Barrett-Connor E, Wingard DL. Type 2 Diabetes and Depressive Symptoms in Older Adults: a Population-based Study. Diabet Med. 1991; 8:532-539.

45. van Dooren FE, Denollet J, Verhey FR, Stehouwer CD, Sep SJ, Henry RM, Kremers SP, Dagnelie PC, Schaper NC, van der Kallen CJ, Koster A, Pouwer F, Schram MT. Psychological and personality factors in type 2 diabetes mellitus, presenting the rationale and exploratory results from The Maastricht Study, a population-based cohort study. BMC Psychiatry. 2016; 16:17.

46. Westra S, Simsek S, Rutters F, Krul-Poel YM, Stehouwer CD, Dekker JM, Pouwer F. Research: Pathophysiology Low vitamin D levels are not a contributing factor to higher prevalence of depressive symptoms in people with Type 2 diabetes mellitus: the Hoorn study. Diabet Med. 2016.

47. Meurs M, Roest AM, Wolffenbuttel BH, Stolk RP, de Jonge P, Rosmalen JG. Association of Depressive and Anxiety Disorders With Diagnosed Versus Undiagnosed Diabetes: An Epidemiological Study of 90,686 Participants. Psychosom Med. 2015; 78:233-241.

48. Deschênes SS, Burns RJ, Schmitz N. Associations between diabetes, major depressive disorder and generalized anxiety disorder comorbidity, and disability: Findings from the 2012 Canadian Community Health Survey-Mental Health (CCHS-MH). J Psychosom Res. 2015; 78:137-142.

49. Bruce DG, Davis WA, Hunter ML, Peters KE, Davis TM, Starkstein SE. Lifetime depression history and depression risk in type 2 diabetes: A case-control study. J Diabetes Complicat. 2015; 30:38-42.

50. Islam SM, Ferrari U, Seissler J, Niessen L, Lechner A. Association between depression and diabetes amongst adults in Bangladesh: Hospital-based case-control study. J Glob Health. 2015; 5:020406.

51. Hamer M, Batty GD, Kivimaki M. Haemoglobin A1C, fasting glucose and future risk of elevated depressive symptoms over 2- years follow up in the English Longitudinal Study of Ageing. Psychol Med. 2011; 41:1889-1896.

52. O'Connor PJ, Crain AL, Rush WA, Hanson AM, Fischer LR, Kluznik JC. Does diabetes double the risk of depression? Ann Fam Med. 2009; 7:328-335.
53. Almawi W, Tamim H, Al-Sayed N, Arekat MR, Al-Khateeb GM, Baqer A, Tutanji H, Kamel C. Association of comorbid depression, anxiety, and stress disorders with Type 2 diabetes in Bahrain, a country with a very high prevalence of Type 2 diabetes. J Endocrinol Invest. 2008; 31:1020-1024.

54. Luijendijk HJ, Stricker BH, Hofman A, Witteman JC, Tiemeier H. Cerebrovascular risk factors and incident depression in community-dwelling elderly. Acta Psychiatr Scand. 2008; 118:139-148.

55. Maraldi C, Volpato S, Penninx BW, Yaffe K, Simonsick EM, Strotmeyer ES, Cesari M, Kritchevsky SB, Perry S, Ayonayon HN, Pahor M. Diabetes Mellitus, Glycemic Control, and Incident Depressive Symptoms Among 70- to 79-Year-Old Persons. Arch Intern Med. 2007; 167:1137-1144.

56. Kim JM, Stewart R, Kim SW, Yang SJ, Shin IS, Yoon JS. Vascular risk factors and incident late-life depression in a Korean population. Br J Psychiatry. 2006; 189:26-30.

57. de Jonge P, Roy JF, Saz P, Marcos G. Prevalent and incident depression in community-dwelling elderly persons with diabetes mellitus: results from the ZARADEMP project. Diabetologia. 2006; 9:2627-2633.

58. Brown LC, Majundar SR, Newman SC, Johnson JA. Type 2 diabetes does not increase risk of depression. CMAJ. 2006; 175:42-46.

59. Polsky D, Doshi JA, Marcus S, Oslin D, Rothbard A, Thomas N, Thompson CL. Long-term Risk for Depressive Symptoms After a Medical Diagnosis. Arch Intern Med. 2005; 165:1260-1266.

60. Bisschop MI, Kriegsman DM, Deeg DJ, Beekman AT, van Tilburg W. The longitudinal relation between chronic diseases and depression in older persons in the community: the Longitudinal Aging Study Amsterdam. J Clin Epidemiol. 2004; 57:187-194.

61. Rajala U, Keinänen-Kiukaanniemi S, Kivelä SL. Noninsulin-dependent diabetes mellitus and depression in a middle.aged Finnish population. Soc Psychiatry Psychiatr Epidemiol. 1997; 32:363-367.

62. Wing RR, Marcus MD, Blair EH, Epstein LH, Burton LR. Depressive Symptomatology in Obese Adults With Type II Diabetes. Diabetes Care. 1990; 13:170-172.

63. Weyerer S, Hewer W, Pfeifer-Kurda M, Dilling $\mathrm{H}$. Psychiatric Disorders and Diabetes-Results from A Community Study. J Psychosom Res. 1989; 33:633-640.

64. Musselman DL, Betan E, Larsen H, Phillips LS. Relationship of depression to diabetes types 1 and 2: epidemiology, biology, and treatment. Biol Psychiatry. 2003; 54:317-329.

65. Rustad JK, Musselman DL, Nemeroff CB. The relationship of depression and diabetes: pathophysiological and treatment implications. Psychoneuroendocrinology. 2011; 36:1276-1286. 
66. Petrak F, Baumeister H, Skinner TC, Brown A, Holt RI. Depression and diabetes: treatment and health-care delivery. Lancet Diabetes Endocrinol. 2015; 3:472-485.

67. Sachs GS, Guille C. Weight gain associated with use of psychotropic medications. J Clin Psychiatry. 2009; 21:16-19.

68. Fava M. Weight gain and antidepressants. J Clin Psychiatry. 2000; 61:37-41.

69. Gragnoli C. Depression and type 2 diabetes: cortisol pathway implication and investigational needs. J Cell Physiol. 2012; 227:2318-2322.
70. Fisher EB, Chan JC, Nan H, Sartorius N, Oldenburg B. Co-occurrence of diabetes and depression: conceptual considerations for an emerging global health challenge. J Affect Disord. 2012; 142:S56-66.

71. Moulton CD, Pickup JC, Ismail K. The link between depression and diabetes: the search for shared mechanisms. Lancet Diabetes Endocrinol. 2015; 3:461-471.

72. Ji HF, Zhuang QS, Shen L. Genetic overlap between type 2 diabetes and major depressive disorder identified by bioinformatics analysis. Oncotarget. 2016; 7:17410-17414. doi: 10.18632/oncotarget.8202. 